\section{DESAFIOS DO ENSINO MÉDIO \\ E POLÍTICAS PÚBLICAS EDUCACIONAIS}

Erinaldo Ferreira do Carmo ${ }^{1}$ José Aercio Silva das Chagas ${ }^{2}$ Dalson Britto Figueiredo Filho

RESUMO

Este artigo é resultado de um trabalho de pesquisa sobre a educação básica, e em especial sobre o Ensino Médio, e as políticas públicas nacionais voltadas para este nível de ensino. Ele descreve e analisa o novo Ensino Médio brasileiro, os seus grandiosos desafios e suas relações com o Ensino Fundamental e com o Ensino Superior, considerando a legislação educacional vigente, o modelo de acesso à universidade e as exigências de conhecimento amplo dos meios produtivos e do mercado de trabalho. Através de dados oficiais são avaliados os investimentos públicos em educação, as metas educacionais estabelecidas e a diferenciação entre o ensino da rede pública e da rede privada.

Palavras-chave: Ensino Médio, Enem, Educação Básica.
CHALLENGES OF THE HIGH SCHOOL AND EDUCATIONAL POLICIES

\title{
ABSTRACT
}

This article is the result of a research work on basic education, especially on the high school, and national public policies aimed at this level. It describes and analyzes the new Brazilian High School, its great challenges and its relations with the Elementary Education and Higher Education, considering the current educational legislation, the model of university entrance and the requirements of broad knowledge of the means of production and labor market. Through official data are evaluated public investment in education, the educational goals established and differentiation between education in public and in private networks.

Keywords: High School. Enem. Basic Education.

1 - Doutor em Ciência Política;

Professor de Sociologia do Colégio de Aplicação do Centro de Educação da UFPE;

Professor de Prática de Ensino em Ciências Sociais na licenciatura do Centro de Educação da

UFPE. - Cel. 8188760083 - e-mail: erinaldocarmo@gmail.com

2 - Doutor em Educação;

Coordenador do Serviço de Orientação e Experimentação Pedagógica do Colégio de Aplicação da UFPE.

3 - Doutor em Ciência Política;

Professor do Departamento de Ciência Política e Relações Internacionais da UFPE. 
Desde a redemocratização do país, na década de 1980, a educação adquiriu novos valores, passando a constar na Carta Magna nacional como um direito universal aos brasileiros: direito de todos e dever do Estado e da família (Art. 205). Na década de 1990, com a reforma educacional promovida pela Lei de Diretrizes e Bases da Educação Nacional - LDB, também identificada como Lei Darcy Ribeiro, em homenagem ao seu árduo defensor, esta relevância da educação foi ratificada e ampliada em seu papel na formação de um novo cidadão para uma nova sociedade em formação. Na década de 2000, a criação do Fundo de Manutenção e Desenvolvimento da Educação Básica e de Valorização dos Profissionais da Educação Fundeb garantiu uma ampliação de recursos para o Ensino Médio, que adquiriu grande relevância na formação do estudante para a cidadania, para o mercado de trabalho e para a universidade, sendo reconhecido como um nível educacional meio, e não como fim, como nos propomos a investigar nesta pesquisa.

Para este trabalho de pesquisa, foram utilizados dados secundários extraídos de fontes oficiais vinculadas ao Governo Federal, como o Instituto Nacional de Estudos e Pesquisas Educacionais Anísio Teixeira - Inep, órgão do Ministério da Educação - MEC responsável pelas avaliações educacionais, e o Instituto Brasileiro de Geografia e Estatística - IBGE para dados referentes ao mercado. Também foram consultados documentos oficiais, como a legislação educacional vigente, e outras publicações recentes, como o Novo Ensino Médio, a Matriz Referencial do Enem e os Protótipos Curriculares, além de artigos acadêmicos sobre o tema.

O tratamento dos dados obtidos se deu, fundamentalmente, de forma quantitativa, mas considerando a educação de forma mais abrangente, sem se limitar aos números, permitindo algumas análises e considerações qualitativas à pesquisa. Assim, produzimos um trabalho que não apenas descreve a natureza do ensino de nível médio, mas também analisa a sua

\section{O novo Ensino Médio}

A solidificação da democracia nacional, aliada às novas tecnologias e às mudanças na forma de produção de bens, serviços e conhecimentos, projetou a escola para as novas dinâmicas e dimensões do mundo contemporâneo, ainda considerando a tarefa da educação na integração dos estudantes às novas ferramentas de inserção à cidadania, ao mercado trabalho e aos estudos posteriores, com o desenvolvimento da capacidade do educando de pesquisar, selecionar e analisar informações, investindo no potencial do aluno para aprender, criar e formular, ao invés da simples memorização.

Este é o grandioso desafio do novo Ensino Médio, apresentado nos Parâmetros Curriculares Nacionais para este nível de ensino, aproximando a escola da nova realidade nacional e colocando o jovem e o adolescente como agentes partícipes desta realidade.

Em sintonia com as necessidades de uma nova sociedade, ainda em transformação, a Constituição Federal de 1988, em seu Art. 208, inciso II, reconhece a relevância deste nível de ensino na formação escolar dos brasileiros quando estabelece como dever do Estado a progressiva extensão da obrigatoriedade do Ensino Médio. E em 1996, através de Emenda Constitucional, este dever do Estado foi ampliado, exigindo a universalização do Ensino Médio, ou seja, conferindo a este nível de ensino o caráter de direito universal a todos os cidadãos.

A nova LDB, Lei 9.394/96, por sua vez, confere ao Ensino Médio o caráter de processo educacional básico para o exercício da cidadania, para o acesso às atividades produtivas e para o prosseguimento nos níveis mais elevados de estudos, fazendo parte da Educação Básica essencial ao país. Em seu Art. 22, a LDB registra que a Educação Básica tem a finalidade de desenvolver o educando, garantindo-lhe a formação cidadã, os meios para progredir no 
trabalho e prosseguir nos estudos. A formação para o exercício pleno da cidadania, como almejado pela LDB, contempla ainda a declaração da Constituição de 1988, que em seu Art. $1^{\text {o }}$ apresenta a cidadania como um dos fundamentos da República Federativa do Brasil.

Adaptado a esta nova realidade, o Ensino Médio tornou-se uma tentativa de integrar, em um mesmo nível, de forma articulada e equilibrada, uma formação humanizada, ética, crítica e autônoma, voltada para o desenvolvimento de valores e competências necessárias à integração do aluno, em seu projeto de vida individual, ao projeto coletivo da sociedade. Também passou a proporcionar uma formação comprometida com o novo significado do trabalho e da política para o cidadão conscientemente produtivo e politicamente ativo, que faz uso desses conhecimentos para se aprimorar no mundo do trabalho e para se envolver na vida política de sua sociedade.

Este envolvimento do cidadão já é visível na política nacional através do acompanhamento dos processos eleitorais que destaca a ampliação da participação do eleitor, desde a primeira década do século XXI, quando foram consolidadas as mudanças estruturais instauradas a partir da redemocratização do país, representadas numa melhoria do eleitorado nacional com a elevação da escolaridade do eleitor e a consequente ascensão da renda e da qualidade de vida, resultando numa participação mais efetiva na política do país.

\section{Do Ensino Médio ao ingresso na universidade}

Um debate recente, levantado no Congresso Nacional, diz respeito à reserva de vagas nas universidades públicas para estudantes oriundos de escolas públicas, além das cotas raciais e étnicas. Esta medida visa democratizar o acesso ao Ensino Superior e ao ensino técnico em nível médio, atendendo à população historicamente menos favorecida. A Lei de Cotas, Lei 12.711/12, prevê que metade das vagas de todos os cursos e turnos das instituições federais seja reservada a alunos que estudaram todo o nível médio em escola pública. Uma parte dessas vagas é reservada a negros, pardos e índios, outra parte à estudantes com renda familiar igual ou menor a 1,5 salário mínimo per capita.

Mesmo antes da Lei de Cotas, já havia uma divisão "aparentemente equilibrada" nas universidades federais. Segundo o levantamento do Perfil Socioeconômico e Cultural dos Estudantes de Graduação das Universidades Federais Brasileiras, realizado em 2011 pela Associação Nacional dos Dirigentes das Instituições Federais de Ensino Superior - Andifes, dos atuais estudantes universitários federais, $44,8 \%$ cursaram todo o Ensino Médio em escolas públicas. Portanto, quase a metade dos estudantes das universidades públicas federais já é oriunda exclusivamente de escolas públicas. Entretanto, o "aparente equilíbrio" na divisão das vagas perde o sentido quando os estudantes são estratificados por curso, visto que entre os cursos de maior concorrência (Medicina, Direito e as Engenharias) a ocupação é quase que exclusiva de alunos oriundos de escolas privadas, enquanto os cursos de menor concorrência, incluindo as licenciaturas, recebem uma participação maior dos estudantes advindos de escolas públicas no preenchimento das vagas.

\begin{tabular}{l|c|c|c}
\cline { 2 - 4 } & $\begin{array}{c}\text { Escola } \\
\text { Pública }\end{array}$ & $\begin{array}{c}\text { Pública e } \\
\text { Particular* }\end{array}$ & $\begin{array}{c}\text { Escola } \\
\text { Particular }\end{array}$ \\
\hline Nordeste & 41,3 & 13,2 & 45,3 \\
\hline Norte & 71,4 & 12,3 & 16,1 \\
\hline Sudeste & 37,0 & 12,4 & 50,5 \\
\hline Sul & 50,5 & 11,7 & 37,7 \\
\hline Centro-Oeste & 40,6 & 14,7 & 44,5 \\
\hline BRASIL & $\mathbf{4 4 , 8}$ & $\mathbf{1 2 , 8}$ & $\mathbf{4 2 , 3}$ \\
\hline
\end{tabular}

Fonte: Andifes, 2011.

*Ao menos um ano foi cursado em rede diferente.

Tabela 1 - Origem dos alunos de graduação das universidades federais (\%) 
A aprovação escolar também é outra característica que diferencia bastante o Ensino Médio nas escolas públicas e privadas. Em todos os anos analisados nesta pesquisa, o aproveitamento é sempre mais expressivo entre as escolas particulares. Paralelamente, os percentuais de repetência e abandono mostram-se maiores nas escolas públicas. A reprovação total no Ensino Médio, em 2011, foi de 13,4\% na rede pública e de 6,3\% na rede privada. A evasão escolar também é bastante superior no Ensino Médio das escolas públicas, em comparação com as privadas e até mesmo em comparação com outros níveis de ensino na rede pública. Enquanto nas escolas particulares o abandono foi de apenas 0,6\% em 2011, nas escolas públicas atingiu 12,6\%. Neste mesmo ano o total de abandono no Ensino Fundamental da rede pública foi de $3,6 \%$.

O número de alunos em sala de aula também é um ponto importante a ser considerado na comparação entre as escolas, visto que o rendimento da classe tende a cair se os professores trabalham com excesso de estudantes por turma. Entretanto, este problema de superlotação não foi revelado nos dados analisados. A quantidade média de alunos por sala é muito próximo na comparação entre ambas as redes, sendo de 31,9 alunos/sala na rede pública e 31,3 alunos/sala na rede privada. Já na comparação entre a quantidade de horas aula/dia verifica-se uma diferença considerável entre as redes. Na média, as escolas públicas cumprem pouco mais de 800 horas anuais, distribuídas nos 200 dias letivos, enquanto a média das escolas privadas ultrapassam 1000 horas anuais. Em parte, a elevação da pontuação dos estudantes das escolas particulares no Exame Nacional do Ensino Médio - Enem está relacionada ao fato destes alunos passarem mais tempo em sala de aula. Para o ano letivo de 2011, a média de horas aula/dia foi de 4,4 na rede pública e de 5, 1 na particular.

De uma forma geral, a maior parte das escolas do país, tanto públicas quanto privadas, situa-se em níveis bem próximos de pontuação no Enem, abaixo de 600 pontos, o que demonstra a similaridade de qualidade do ensino em ambas as redes. $\mathrm{O}$ aluno de uma escola com qualidade inferior é penalizado em sua aprendizagem, independente dela ser pública ou privada. Mas o que causa tamanha diferenciação na pontuação geral do Enem se o nível de qualidade das escolas é tão próximo?

A diferença está na pontuação de poucas escolas de elevada qualidade de ensino, que puxam a média do seu grupo para cima. Como há mais escolas de boa qualidade na rede privada, estas elevam a média de todas as particulares, quando considerada a rede como um todo. Para se ter uma ideia, apenas 10 escolas obtiveram uma pontuação superior a 700 pontos no Enem de 2011. Destas, nove são particulares e apenas uma é pública. Agora, considerando o total das escolas que ficaram com média acima de 600 pontos, 898 são privadas e apenas 76 são públicas. Resultado: 18,7\% das escolas da rede privada ficaram com médias acima de 600 pontos e na rede pública somente $1,4 \%$ das escolas atingiram ou ultrapassaram esta média, ou seja, são pouquíssimas as escolas públicas que puxam a média desta rede para cima.

Mesmo entre as públicas, registra-se uma enorme distorção quando comparadas pelos níveis de gestão. Enquanto as federais até ultrapassam a média da pontuação das privadas, as estaduais, a quem cabe obrigatoriamente a oferta do Ensino Médio, se afastam das federais em mais de 80 pontos. E a diferença na proficiência em Matemática e Redação chega a ultrapassar 100 pontos.

\begin{tabular}{|c|c|c|c|c|c|}
\hline & \multicolumn{3}{|c|}{ Públicas } & \multirow[b]{2}{*}{ Privadas } & \multirow{2}{*}{$\begin{array}{l}\text { Total } \\
\text { Geral }\end{array}$} \\
\hline & Estaduais & Municipais & Federais & & \\
\hline $\mathrm{N}^{\circ}$ escolas & 4.968 & 111 & 199 & 4.798 & 10.076 \\
\hline $\mathrm{N}^{\mathrm{o}}$ alunos & 345.508 & 6.866 & 19.893 & 184.799 & 557.066 \\
\hline $\mathrm{CN}$ & 449 & 473 & 535 & 529 & 489 \\
\hline $\mathrm{CH}$ & 456 & 481 & 539 & 531 & 494 \\
\hline LC & 504 & 528 & 570 & 569 & 537 \\
\hline MT & 498 & 533 & 624 & 611 & 555 \\
\hline Redação & 506 & 544 & 611 & 612 & 559 \\
\hline Média Geral & 477 & 504 & 567 & 560 & 519 \\
\hline
\end{tabular}

CN = Ciências da Natureza e suas tecnologias (Química, Física e Biologia)

$\mathrm{CH}=$ Ciências Humanas e suas tecnologias (Geografia, História, Filosofia e Sociologia) LC = Linguagens, códigos e suas tecnologias (Língua Portuguesa, Línguas Estrangeiras e Literatura) MT = Matemática e suas tecnologias

Tabela 2 - Pontuação média das escolas - Enem 2011 - Fonte: Inep-MEC 
Um dos problemas detectados na avaliação no Enem é a redução na pontuação referente às provas das ciências da natureza. Em parte, esta problemática não é decorrente apenas da exigência de cálculos, mas também da dificuldade de relacionamento entre os conteúdos trabalhados, sua contextualização e aplicabilidade na vida do estudante. Segundo Morin (2003), uma falha do ensino regular está na compartimentalização dos saberes, ou na incapacidade de articulá-los, de forma interdisciplinar, e contextualizá-lo de forma a se aproximar da vida real do aluno.

Estas deficiências não sanadas no Ensino Médio, dificilmente serão resolvidas no ensino superior, onde a abordagem e complexidade dos conteúdos são diferentes e tornam-se um fator complicador nessa esfera do ensino. O que ocorre na verdade é uma transposição deste problema do Ensino Médio da rede pública para o Ensino Superior da rede privada, isto porque os estudantes de nível médio da rede privada ao obterem melhores pontuações no Enem garantem para si as vagas mais concorridas das universidades públicas, enquanto os estudantes de nível médio da rede pública, com defasagem de conteúdos, são transportados para a rede privada no ensino universitário. Para tentar corrigir esta competição desigual, a Lei de Cotas estabeleceu uma divisão de $50 \%$ das vagas nas universidades públicas para cada rede de ensino.

Para efeito comparativo, enquanto no Ensino Médio 66,8\% dos estudantes estão atualmente matriculados em escolas públicas, no Ensino Superior a disposição se inverte sobremaneira. De acordo com o Censo da Educação Superior, a extensa maioria dos alunos universitários está matriculada em instituições particulares. Ainda em 2001, considerando a totalidades dos universitários matriculados em cursos de graduação (presencial e a distância), $31,1 \%$ estavam em instituições públicas e 68,9\% em instituições particulares. Já em 2010, apesar da ampliação do número de vagas nas universidades federais, 25,8\% estavam em instituições públicas e 74,2\% nas particulares.

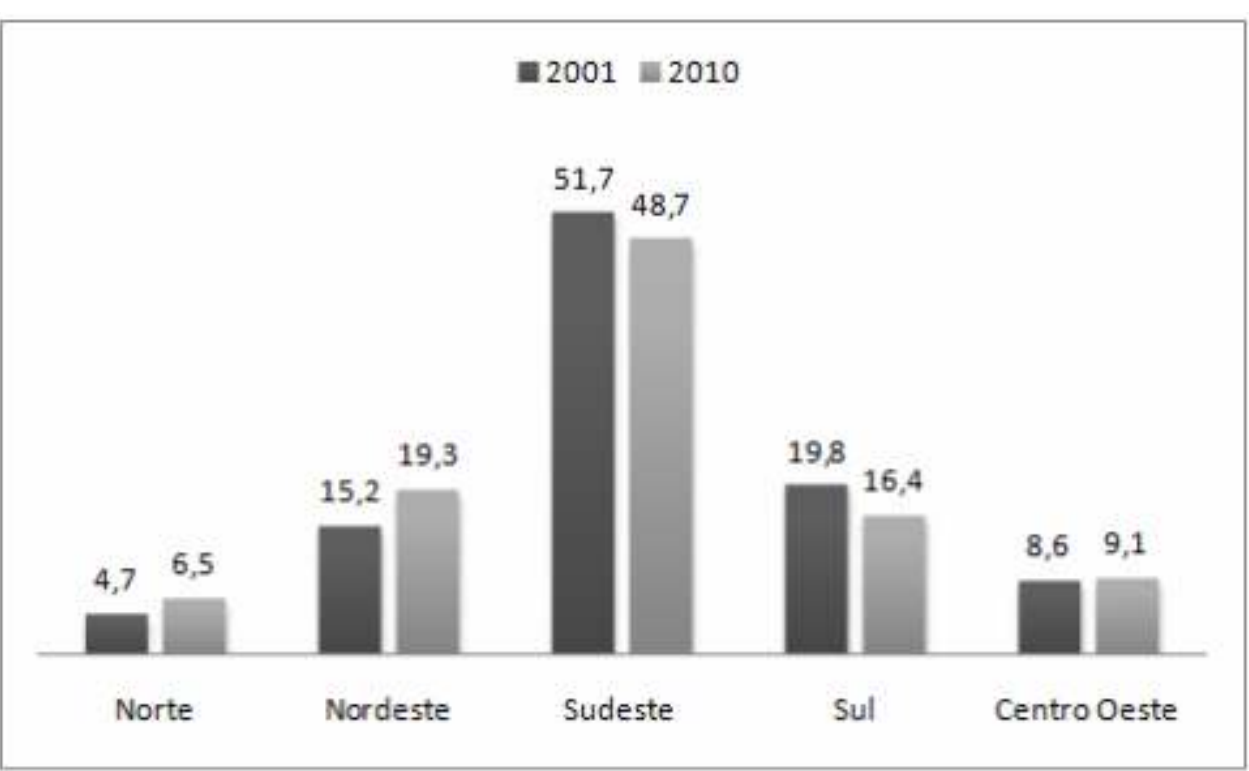

Gráfico 1 - Alunos matriculados na graduação - Brasil (\%) Fonte: Inep-MEC

Em 2001 havia em todo o país três milhões de estudantes universitários. Em 2010 este quantitativo saltou para 5,4 milhões. A abertura de novas universidades e de novos cursos, através do Programa de Apoio a Planos de Reestruturação e Expansão das Universidades Federais - Reuni, além da ampliação dos já existentes, colocou nas universidades públicas um considerável quantitativo de novos estudantes, mas este incremento não se mostra tão expressivo na proporcionalidade devido ao crescimento contínuo do ensino superior privado, com uma constante demanda da sociedade por cursos universitários, em especial no Norte e no Nordeste, onde, proporcionalmente, o crescimento foi mais significativo.

\section{Do Ensino Médio ao mercado de trabalho}

O discurso comum, e que conhecemos pela experiência política vivida pelo país em tempos recentes, é de que a educação produz o desenvolvimento da economia. Seria o 
conhecimento promovendo o mercado. Neste sentido, o antigo Ensino de $2^{\circ}$ Grau, regulado pela Lei 5.692/71, atribuía a este nível de ensino a dupla finalidade de capacitar para o mercado trabalho, com uma formação técnica, e preparar para o prosseguimento dos estudos, como um caminho para a universidade. Isto porque nas décadas de 1960 e 1970, com o elevado desenvolvimento da industrialização no país, a política educacional priorizou a formação de mão de obra capacitada para a produção mecanizada. Todavia, na prática, a dupla finalidade não se cumpriu. $\mathrm{O}$ Ensino Médio tornou-se uma modalidade de ensino que nem atendia às exigências da industrialização, tampouco conseguia desempenhar o papel propedêutico de outras ocasiões.

Com a profissionalização compulsória, o governo tentou atender ao emergente mercado de trabalho industrial, com a formação de especialistas em nível secundário, capazes de dominar a utilização das máquinas, e ao mesmo tempo buscou reduzir a demanda dos alunos

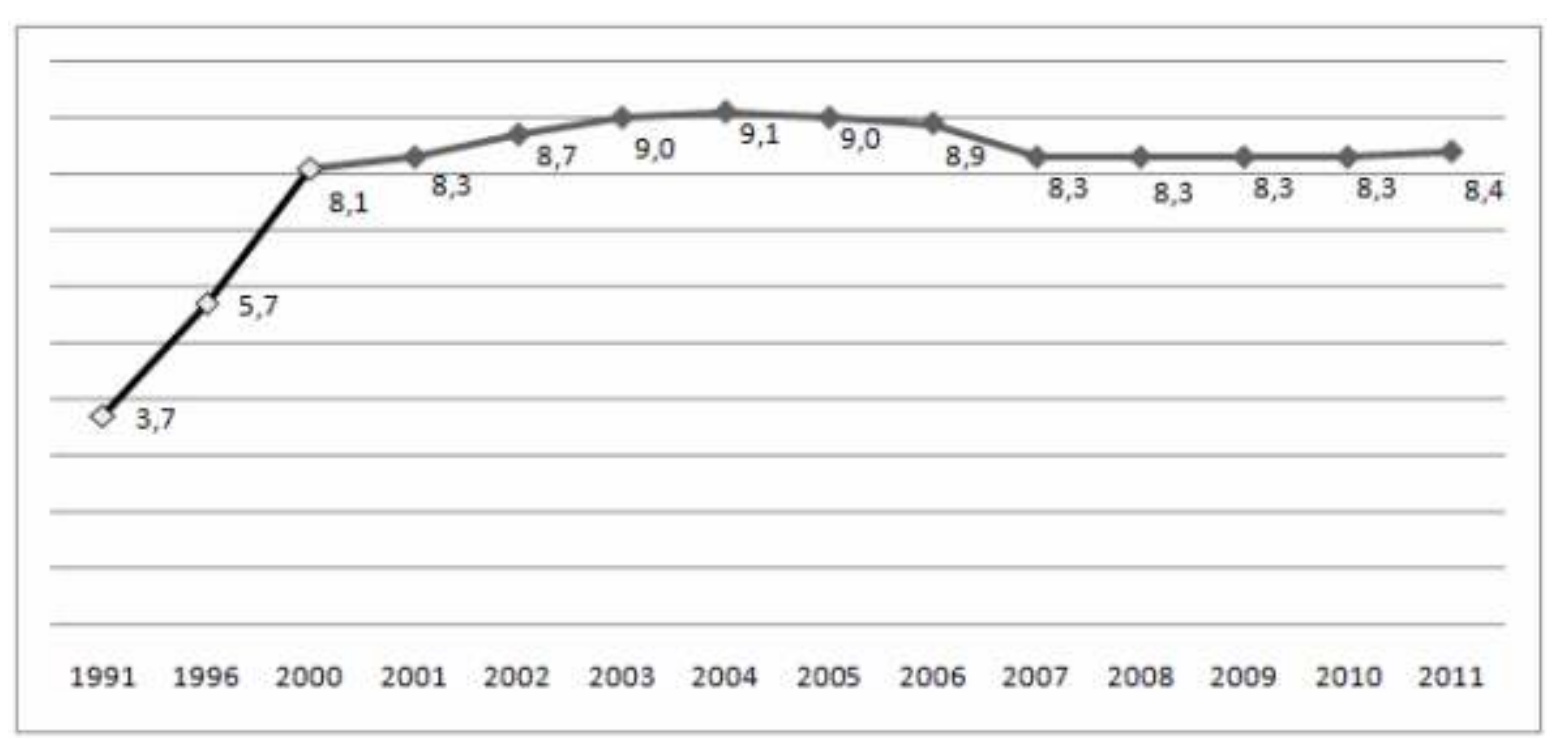

Gráfico 2 - Alunos matriculados no Ensino Médio (em milhões) Fonte: Inep-MEC secundaristas pelo Ensino Superior, que persistia e crescia como demanda represada.

Porém, desde a última década do século passado, temos observado que o caminho é de mão dupla: não só a educação promove a economia, mas também a economia de mercado promove a busca pela educação; não só a educação pode gerar capital humano que possibilite o aperfeiçoamento do mercado, como o mercado pode promover a busca pelo saber e pelo aprimoramento, isto é, a busca dos meios e das condições de sustentação pelo acesso ao conhecimento. A ascensão econômica em determinadas localidades do país fez crescer, ao menos nestas localidades, a corrida pelo ensino, o que trouxe de volta à sala de aula estudantes e trabalhadores preocupados em alcançar as exigências do mercado, cada vez mais restrito em oportunidades aos profissionais mais qualificados. Neste caso, foi o mercado quem incentivou a educação, com a economia propiciando aos trabalhadores a valorização e o investimento no ensino, a exemplo do crescimento dos cursos superiores de instituições privadas, além da maior procura pelo Ensino Médio regular, como principal meio de acesso à universidade.

As matrículas no Ensino Médio passaram de 5,7 milhões em 1996 para 8,3 milhões em 2001. Em 2006 esse crescimento não foi tão elevado, passando para 8,9 milhões de matriculados e em 2011 recuou para 8,4 milhões. Esta procura pelo Ensino Médio, que cresceu vertiginosamente na década de 1990 e continuou em alta, porém moderada, no início da década seguinte, até manter-se numa constância nos últimos quatro anos, está relacionada ao desenvolvimento econômico nacional e à geração de mais postos de trabalho oriundos, dentre outros fatores, do crescimento na produção industrial do país. Obviamente, esta alta no registro das matrículas no Ensino Médio também é verificada nos cursos técnicos e na EJA, acompanhando, paralelamente, a mesma elevação das matrículas na educação superior. 


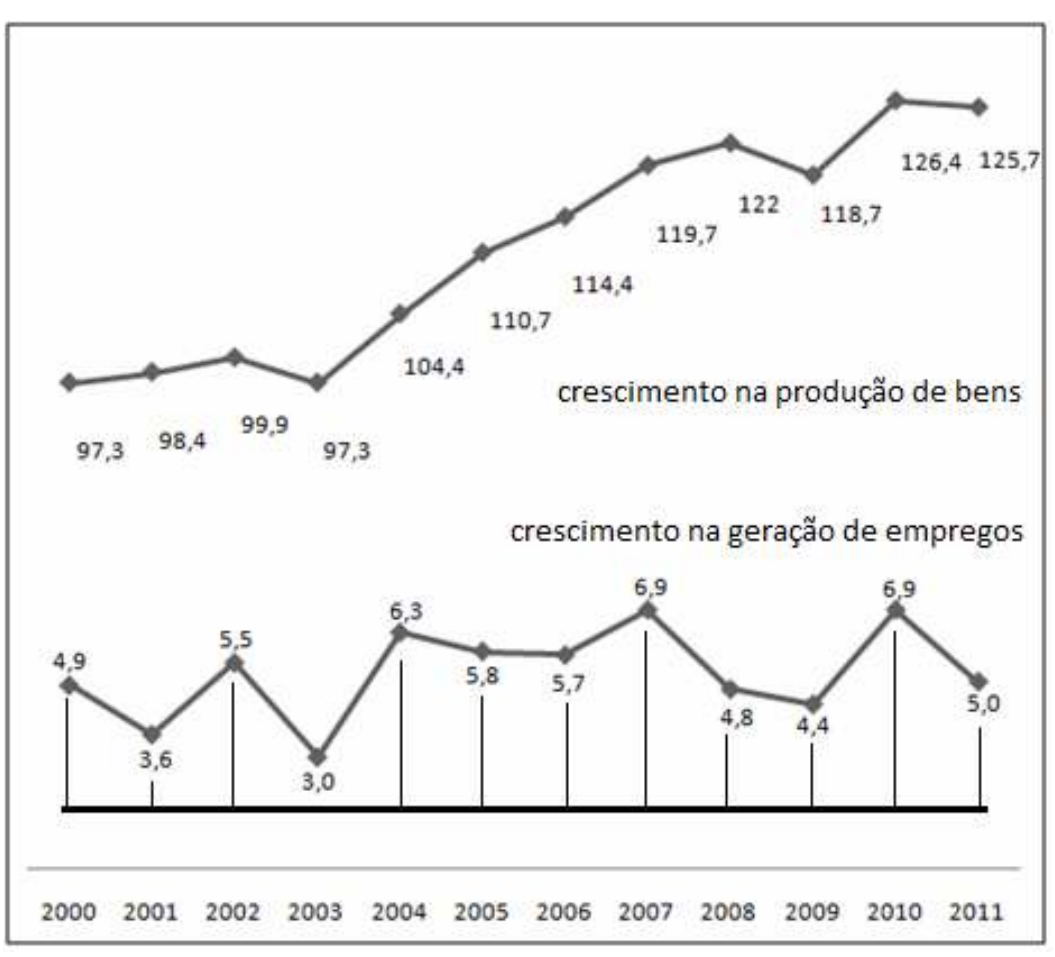

Gráfico 3 - Elevação na produção de bens e geração de empregos Fonte: IBGE

O mercado possui agora uma necessidade imediata de aproximação com o meio científico. As recentes mudanças ocorridas no mercado produtivo apontam para uma nova relação entre a escola e o trabalho, entre o conhecimento e o mercado. Como observa Kuenzer (2000), agora as ações dos sujeitos precisam articular o conhecimento científico, a capacidade cognitiva e a habilidade para intervenções críticas diante de situações inesperadas, que exijam soluções rápidas, originais e fundamentadas.

Com a dimensão adquirida pela sociedade brasileira na política e na economia global, nos últimos anos, o Ensino Médio está desafiado a se aproximar cada vez mais do mercado e da universidade, não se furtando a esta realidade. Assim, a LDB acrescentou ao Ensino Médio a responsabilidade da formação para o exercício da cidadania, mas não desconsiderou as duas finalidades anteriores, do mercado e da universidade. Com isto, este nível escolar foi elevado em suas responsabilidades a um plano que extrapola imensamente o espaço da sala de aula e da escola, cabendo-lhe preparar este novo cidadão para uma nova sociedade em transformação, como ser partícipe da vida social e política em sua coletividade, e ainda habilitar este cidadão para o mercado de trabalho, para o processo produtivo e para os estudos futuros.

\section{$O$ custo por estudantes}

Até o final da última década do século passado, menos de $50 \%$ de toda a população brasileira com idade entre 15 e 17 anos estava matriculada no Ensino Médio. Dos países da América do Sul, apenas o Peru, a Colômbia e o Equador estavam em situação semelhante ou um pouco melhor que o Brasil. No Chile, $73 \%$ dos estudantes com idade escolar apropriada para frequentar o Ensino Médio estavam devidamente matriculados. Na Argentina eram $76 \% \mathrm{e}$ no Uruguai $81 \%$. Somente o Paraguai, com 37\%, e a Bolívia, com 40\%, encontravam-se em situação inferior.

No Brasil, as ações estatais para corrigir esta lacuna foram inicialmente tímidas e ainda não conseguiram produzir os efeitos esperados. Apesar do elevado crescimento nas matrículas no Ensino Médio na década de 1990, este efeito ainda foi insuficiente por não atender a larga parcela da população em idade escolar que deveria frequentar o curso de nível médio. Neste período, a ausência de políticas públicas para este nível de ensino mostra que a demanda surgida foi muito mais por pressão do mercado do que por ação estatal.

Com a ação política de criação do Fundo de Manutenção e Desenvolvimento do Ensino Fundamental e de Valorização do Magistério - Fundef, que vigorou de 1997 a 2006, foram atendidas as necessidades de universalização do Ensino Fundamental, promovendo a consequente ampliação da demanda pelo Ensino Médio. Entretanto, ao priorizar o Ensino 
Fundamental, o Fundef agravou a situação dos Estados que não dispunham de recursos suficientes para atender a esta população concluinte do Ensino Fundamental e que deveria ingressar automaticamente no Ensino Médio.

Só com a implementação do Fundeb, em 2007, é que foi dado um passo importante na universalização do Ensino Médio. O aporte do Governo Federal ao Fundeb iniciou com R \$ 2 bilhões em 2007 e passou para R \$ 5,3 bilhões em 2010. Entretanto, o quantitativo de alunos matriculados neste espaço de tempo não foi ampliado, ao contrário, caindo de 8,9 milhões em 2006 para 8,4 milhões em 2011. É esperado que agora o Ensino Médio tenha entrado numa certa regularidade e este quantitativo passe a ser constante para os próximos anos. Porém, este nível de ensino ainda é um mundo distante para muitos jovens brasileiros, principalmente pela necessidade de trabalho que o jovem das camadas menos favorecidas apresenta. Por isso há a necessidade de políticas de incentivo ao ingresso e à permanência dos estudantes no Ensino Médio, onde as elevadas taxas de reprovação e evasão, correspondentes a 13,4\% e 12,6\%, respectivamente, nas escolas públicas em 2011 servem de alerta para o considerável quantitativo de jovens que têm sua formação interrompida.

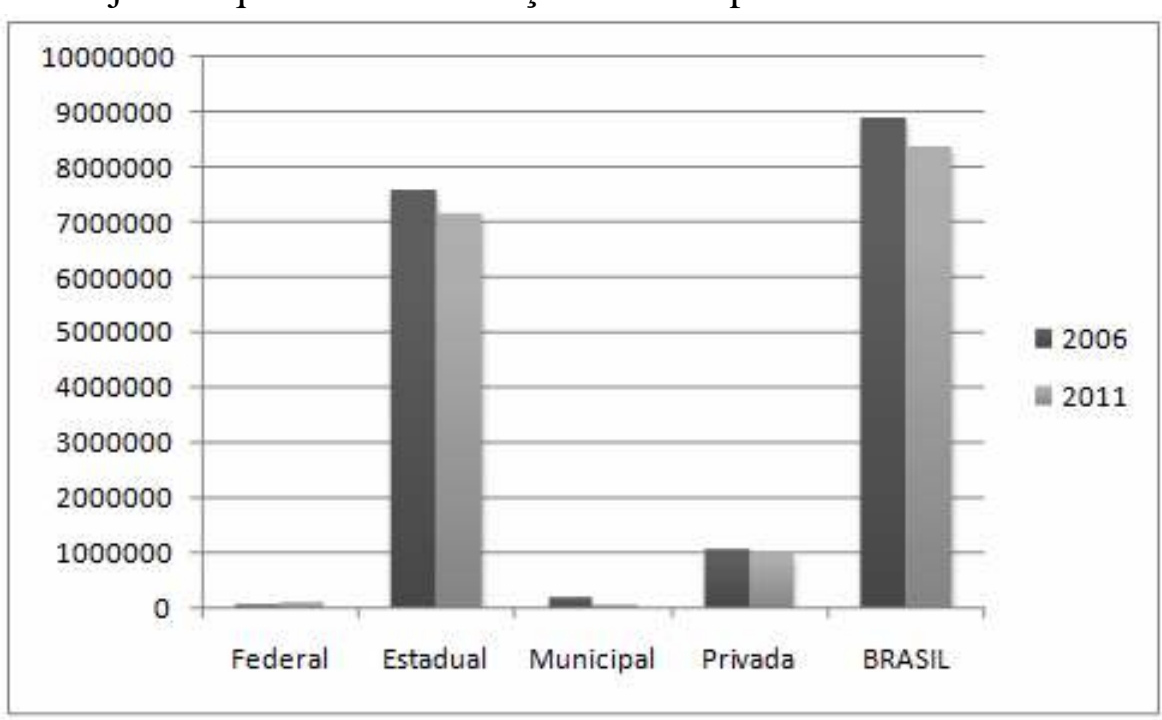

Gráfico 4 - Alunos matriculados no Ensino Médio - Fonte: Inep-MEC

Para reduzir esta distorção e ingressar os concluintes do Ensino Fundamental diretamente no Ensino Médio, bem como atrair alunos fora de faixa para a conclusão deste curso, faz-se necessário o investimento adequado neste nível educacional, visto que o Ensino Médio recebe, proporcionalmente, a menor fatia do investimento público em ensino. Na média histórica, considerando o período de 2000 a 2010, o custo/ano de um aluno do nível médio é inferior ao custo de um aluno em todos os outros níveis, ficando abaixo do infantil, do fundamental I, do fundamental II e sete vezes abaixo do nível superior.

Em 2011, o gasto público com educação representou 5,3\% do Produto Interno Bruto PIB do país. Este valor não está tão abaixo dos gastos das nações ricas. A média entre os países da Organização para a Cooperação e Desenvolvimento Econômico - OCDE é de 6\% do PIB. Entretanto, para que o Ensino Médio seja favorecido e devidamente valorizado, carece de uma implementação de recursos de forma a tornar menos desigual o custo de cada aluno por nível escolar. Para isto, o Art. 10 da Lei 11.494/07, que regulamenta o Fundeb, prevê a distribuição proporcional de recursos entre os níveis e modalidades da Educação Básica, incluindo o nível médio, contemplando o Ensino Médio urbano, o Ensino Médio no campo, o Ensino Médio em tempo integral, o Ensino Médio integrado à educação profissional e o Ensino Médio na EJA.

\begin{tabular}{l|r|r|r|r|r|r|r}
\hline & $\begin{array}{r}\text { Gasto por aluno } \\
\text { (Total Geral) }\end{array}$ & $\begin{array}{r}\text { Educação } \\
\text { Infantil }\end{array}$ & $\begin{array}{r}\text { Ensino } \\
\text { Fundamental 1 }\end{array}$ & $\begin{array}{r}\text { Ensino } \\
\text { Fundamental 2 }\end{array}$ & $\begin{array}{r}\text { Ensino } \\
\text { Médio }\end{array}$ & $\begin{array}{r}\text { Educação Básica } \\
\text { (Total) }\end{array}$ & $\begin{array}{r}\text { Ensino } \\
\text { Superior }\end{array}$ \\
\hline 2000 & 1.842 & 1.753 & 1.508 & 1.539 & $\mathbf{1 . 4 6 2}$ & 1.533 & 16.948 \\
\hline 2001 & 1.907 & 1.583 & 1.491 & 1.677 & $\mathbf{1 . 6 6 4}$ & 1.590 & 16.750 \\
\hline 2002 & 1.902 & 1.491 & 1.741 & 1.616 & $\mathbf{1 . 1 7 1}$ & 1.575 & 15.879 \\
\hline 2003 & 1.905 & 1.716 & 1.686 & 1.602 & $\mathbf{1 . 3 4 4}$ & 1.600 & 13.913 \\
\hline 2004 & 2.016 & 1.828 & 1.810 & 1.830 & $\mathbf{1 . 2 5 1}$ & 1.710 & 14.085 \\
\hline 2005 & 2.143 & 1.731 & 2.025 & 1.929 & $\mathbf{1 . 2 6 6}$ & 1.815 & 14.324 \\
\hline 2006 & 2.495 & 1.873 & 2.230 & 2.449 & $\mathbf{1 . 7 3 2}$ & 2.167 & 14.446 \\
\hline 2007 & 2.886 & 2.286 & 2.660 & 2.771 & $\mathbf{2 . 0 2 9}$ & 2.531 & 15.313 \\
\hline 2008 & 3.309 & 2.438 & 3.050 & 3.254 & $\mathbf{2 . 3 4 4}$ & 2.908 & 16.309 \\
\hline 2009 & 3.581 & 2.411 & 3.393 & 3.539 & $\mathbf{2 . 4 7 4}$ & 3.148 & 16.503 \\
\hline 2010 & 4.087 & 2.942 & 3.859 & 3.905 & $\mathbf{2 . 9 6 0}$ & 3.580 & 17.972 \\
\hline
\end{tabular}

Tabela 3 - Investimento público em educação - por aluno (R \$) - Fonte: Inep-MEC

Vol.6, n.1, p.1-77 ～/ jan./jun./2013 ISSN 1983-8921 


\section{Homogeneidade dos conteúdos}

Ao instituir as Diretrizes Curriculares Nacionais para o Ensino Médio, a Câmara de Educação Básica, através da Resolução no 3, de 26 de junho de 1998, determinou que da carga horária mínima para o Ensino Médio (2.400 horas, equivalentes a três anos de duração), ao menos $75 \%$ compreenderá a Base Nacional Comum.

ALDB, por sua vez, já exige de cada rede de ensino e de cada unidade escolar uma Base Nacional Comum para a Educação Básica, no que inclui o Ensino Médio, orientando que esta base comum deve ser complementada por uma parte diversificada, que deve compreender as características sociais, culturais, econômicas e regionais. O Art. 26 insere, obrigatoriamente, nesta Base Nacional Comum o estudo da Língua Portuguesa, da Matemática, o conhecimento do mundo físico e natural, da realidade social e política, o ensino da arte e a Educação Física. E o Art. 36, parágrafo $1^{\circ}$, estabelece como competências que o aluno deve demonstrar ao final do Ensino Médio, o domínio dos princípios científicos e tecnológicos, das formas de linguagem, dos conhecimentos filosóficos e sociológicos para o exercício da cidadania.

A exigência da legislação educacional para a existência desta base mínima de conteúdos no âmbito nacional é uma providência de equalização dos conhecimentos para todos os estudantes de um mesmo nível educacional. Isto tenta garantir que em qualquer escola, pública ou privada, em qualquer região do país, os alunos sejam submetidos aos mesmos conteúdos e ao mesmo nível de aprendizagem. A aplicação de conteúdos semelhantes ainda favorece a política educacional do Governo Federal de aplicação de exames uniformes em todos os Estados, permitindo a realização de uma avaliação nacional. Haveria uma impossibilidade metodológica de aplicação de um exame coletivo e nacional caso cada unidade escolar ou sistema de ensino trabalhasse temas completamente diferenciados ou

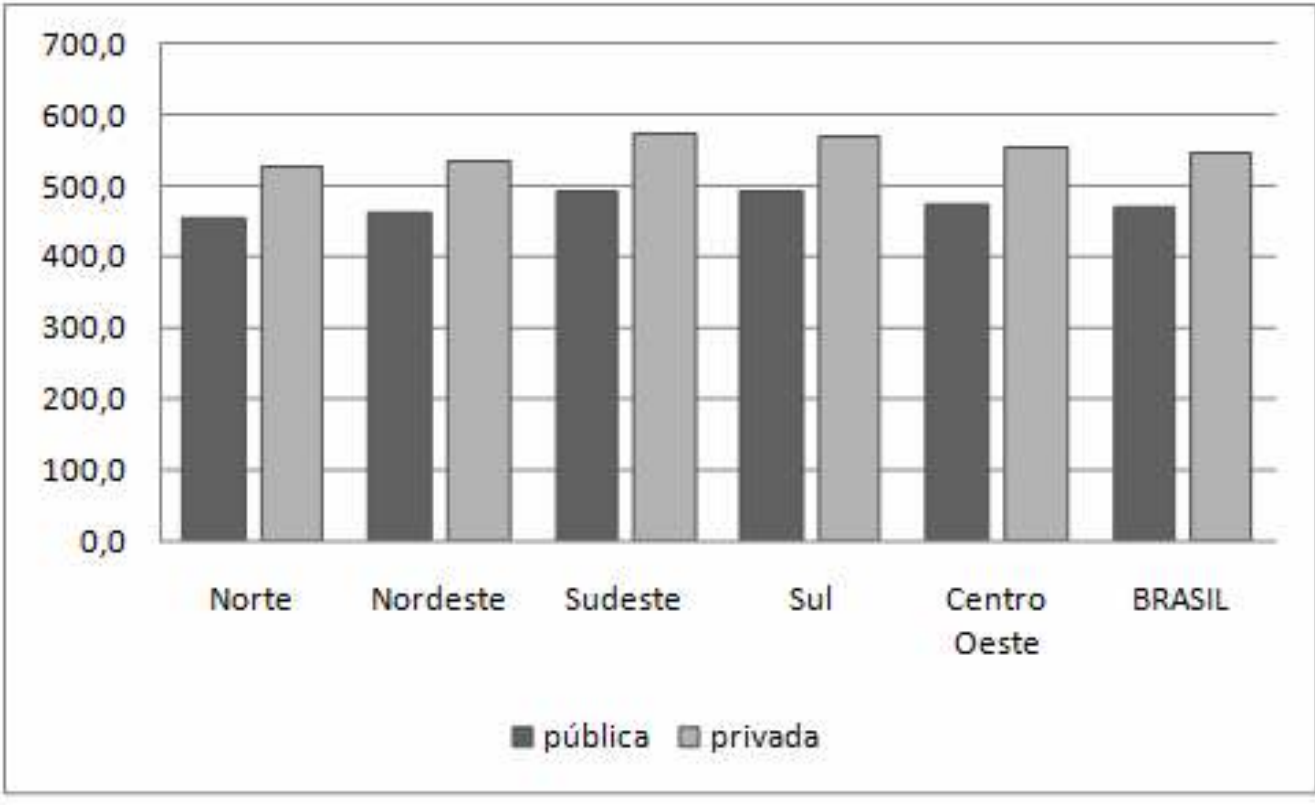

Gráfico 5 - Avaliação Enem 2011 - Regiões - Fonte: Inep-MEC

aleatórios, ou mesmo se selecionassem as disciplinas fora de um padrão nacional.

Ao analisarmos os resultados nacionais do Enem, percebemos que as diferenças regionais não são alarmantes. Entretanto, percebemos que há um fosso entre o ensino público e o privado. Em todas as regiões a diferença entre o ensino público e o privado é ostensiva, demonstrando a existência de um grave problema nacional. A diferença entre a média nacional das escolas públicas (470) e média as privadas (545) é de 75 pontos. As maiores diferenças entre escolas públicas e privadas foram registradas pelo Enem de 2011 no Espírito Santo (100 pontos) e no Tocantins (103 pontos), porém, em nenhum Estado a pontuação média das escolas públicas supera a média das particulares. 


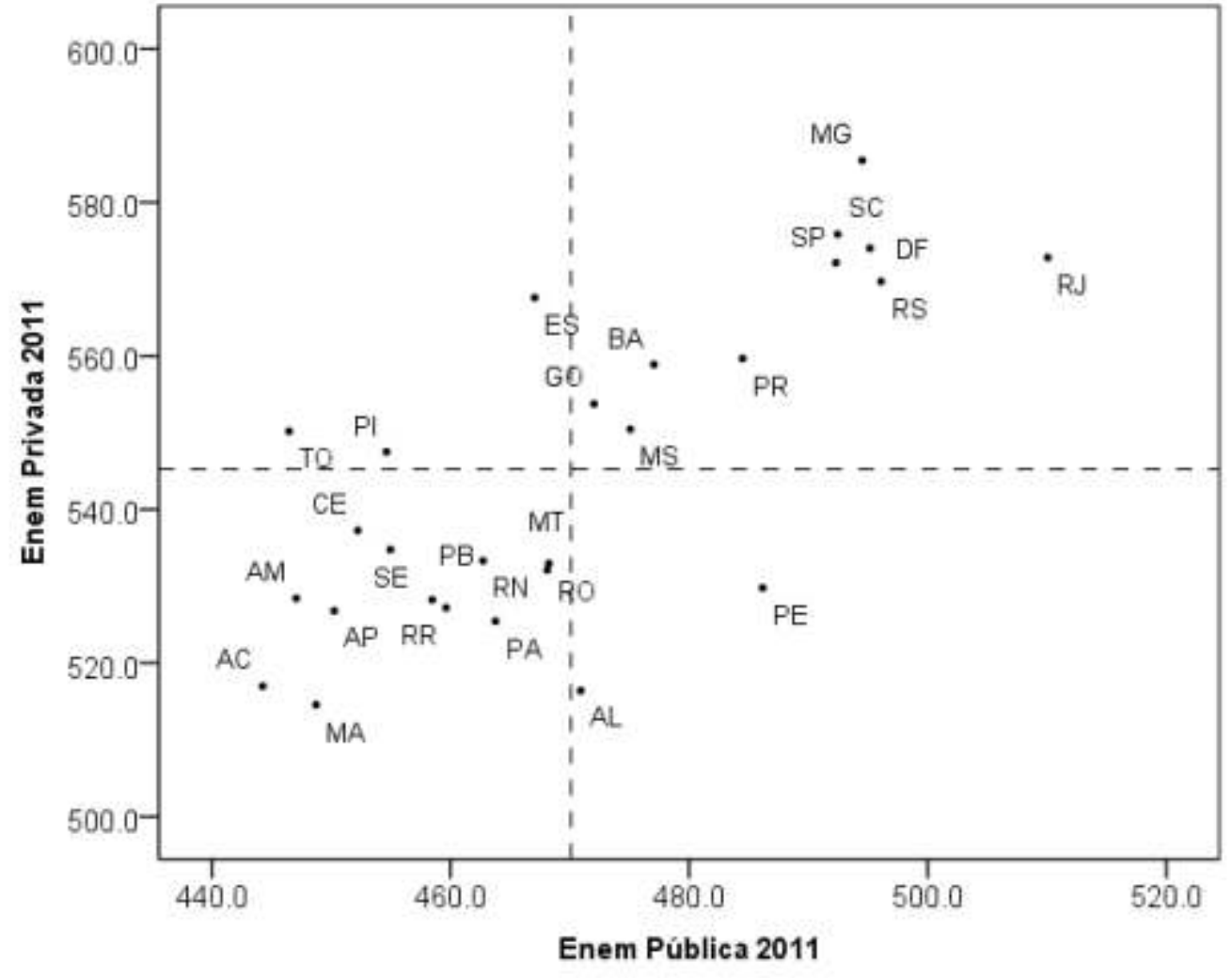

Gráfico 6 - Avaliação Enem 2011 - público versus privado

No Gráfico 6 as linhas pontilhadas indicam as médias das notas do Enem por Estado. A linha horizontal (545) representa a rede privada e a linha vertical (470) representa a rede pública. Existe uma correlação positiva $(0,760)$ e estatisticamente significativa (p - valor < $0,000)$ entre as notas do sistema privado e do sistema público. Todos os estados localizados no quadrante inferior esquerdo apresentam notas do Enem abaixo da média em ambos os sistemas. Comparativamente, essas unidades da federação apresentaram os piores desempenhos. O Rio de Janeiro registra a maior média da rede pública (510) e Minas Gerais apresenta a maior média geral (585) considerando as redes pública e privada.
Ao assumir o compromisso de atender a toda a população na faixa etária de 15 a 17 no Ensino Médio, independente de classe social, o Estado precisa dar destaque ao papel da escola pública nessa missão. Como identifica Kuenzer (2000), para reduzir as diferenças é preciso a construção de uma proposta pedagógica que possibilite meios de aprendizagem aos estudantes da rede pública de ensino que, de um modo geral, registram uma deficiência econômica que se transforma em dificuldades sociais e culturais.

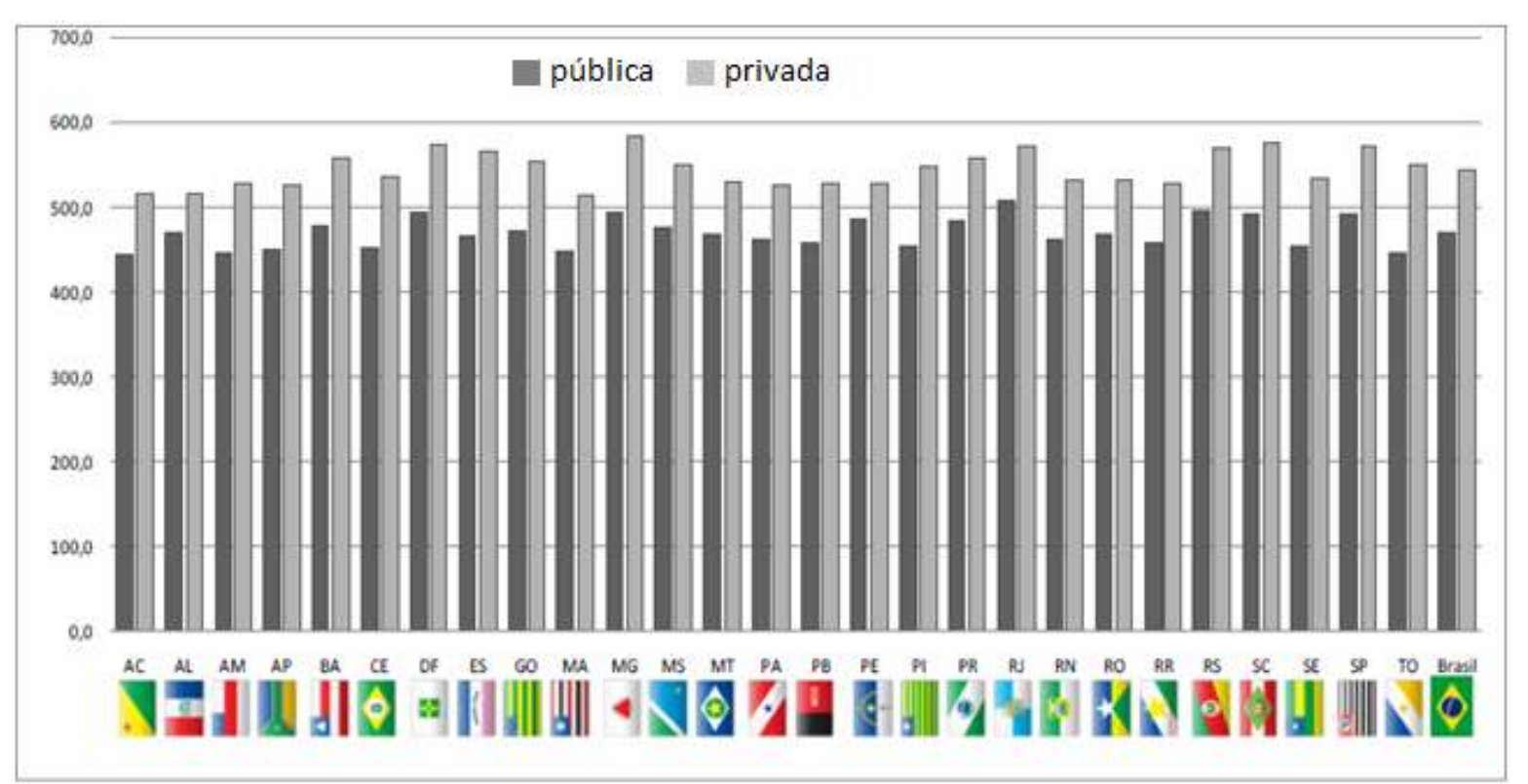

Gráfico 7 - Avaliação Enem 2011 - Estados - Fonte: Inep-MEC

As ações para a melhoria na qualidade do ensino na rede pública são diversas, mas dentre elas também merece destaque a adequada formação do corpo docente. Pinheiro (2007) chama a atenção para a necessidade de se dar uma atenção especial ao profissional do ensino, de quem as mudanças exigem uma formação continuada. Além de um maior investimento no aluno, da melhoria nas estruturas física e organizacional da escola, na aplicação da legislação educacional, é preciso um olhar atento sobre o professor, não bastando reformar os currículos das licenciaturas, mas valorizar o licenciado. A permanente capacitação dos atuais docentes, a 
contratação de novos professores com formação apropriada e o incentivo aos cursos de pósgraduação são metas essenciais para as políticas públicas da educação nacional.

O avanço do Ensino Médio depende, inevitavelmente, dos recursos federais do Fundeb e das ações de cada unidade federativa. Isto porque dentre todas as escolas públicas de Ensino Médio 94,1\% são estaduais. Atento a isto, o Plano Nacional de Educação - PNE, assinado em janeiro de 2001, estabeleceu como meta para o Ensino Médio o atendimento de $100 \%$ da população na faixa etária de 15 a 17 anos e a elevação nas taxa de promoção para $98 \%$, enquanto a repetência e a evasão cairiam para $1 \%$ cada. As metas não foram atingidas no período esperado e por isso foram mantidas para o período seguinte, de 2006 a 2011 . Outra vez não foram alcançadas: a taxa de aprovação chegou a 76,2\% no total geral, envolvendo as escolas públicas e privadas, o que representa uma melhoria, mas ainda não atingiu a meta estipulada. Já os percentuais de reprovação e abandono continuam muito distantes do planejado.

Desta vez o PNE para o decênio 2011-2020 estabeleceu como metas para o Ensino Médio, dentre outras:

- até 2016 universalizar o atendimento a 100\% da população de 15 a 17 anos;

- até 2020 oferecer educação em tempo integral em 50\% das escolas públicas;

- até 2020 formar 50\% dos professores da Educação Básica em nível de pós-graduação;

- ampliar progressivamente o investimento público em educação até atingir, no mínimo, o patamar de $7 \%$ do PIB nacional.

\section{Considerações finais}

A conclusão deste trabalho representa uma contribuição aos recentes estudos quantitativos que envolvem a educação nacional, compreende o debruçar sobre os números da educação e uma análise desses números no contexto do Ensino Médio. No Brasil, o uso de dados quantitativos em pesquisas educacionais não era muito comum até pouco tempo atrás, como acentua Gatti (2004), inclusive pela então ausência de informações oficiais, o que dificultava o uso de recursos estatísticos na análise mais consistente deste tema. Este fato começou a mudar recentemente com a coleta e divulgação de dados educacionais através do Inep. Daí o surgimento de novas análises sobre a educação nacional e a presença mais acentuada de pesquisas quantitativas em apresentações e publicações científicas.

Ao analisarmos aqui os dados educacionais em um período de tempo ampliado, percebemos o quanto os investimentos públicos precisam ser melhor distribuídos, atendendo satisfatoriamente o Ensino Médio, principalmente agora que este nível adquiriu caráter definido na LDB, tendo sua relevância estendida com uma tripla incumbência: a formação para a cidadania, a preparação para o mercado e a capacitação para os estudos superiores.

No acesso à universidade pública é importante que os estudantes secundaristas da rede pública não tenham o seu ingresso garantido apenas por força de lei, mas possam receber a mesma capacitação que os estudantes das melhores escolas privadas. Atualmente, como registra Matos (2012), o egresso da escola pública é desestimulado a prestar vestibular por considerar que são poucas suas chances de aprovação. Assim, notamos que este é o maior desafio do Ensino Médio das redes públicas estaduais devido a sua formação segregadora, não só entre escolas públicas e privadas, mas também entre escolas do centro e da periferia e escolas urbanas e rurais.

Ao ensino público cabe o papel de também atender à parcela excluída da população. Consequentemente, o desempenho de suas escolas no Enem reflete as carências trazidas por esses alunos. Porém, a mesma rede que deveria equalizar as relações entre o seu alunado, tornase acintosamente segregada quando concentra os estudantes pobres em unidades educacionais deficitárias. Mesmo na rede pública há uma nítida distinção entre as unidades de ensino: as melhores são urbanas e centrais, em oposição às escolas rurais e periféricas, onde, em geral, os problemas operacionais, estruturais e pedagógicos são mais gritantes. Como resultado, as 
comunidades mais pobres ficam com as escolas menos atrativas e os problemas básicos que atingem os alunos em casa também os afetam no ambiente escolar.

\section{Bibliografia}

BRASIL. Constituição da Republica Federativa do Brasil. Brasília: Senado Federal, 1988 Lei de Diretrizes e Bases da Educação Nacional. Brasília: Diário Oficial da União, 1996.

Parâmetros Curriculares Nacionais: Ensino Médio. Brasília: MEC - Secretaria de Educação Média e Tecnológica, 1999.

Plano Nacional de Educação 2011-2020. Disponível em < mec.gov.br >. Acessado em 18 fev. 2013.

GATTI, B. A. Estudos quantitativos em educação. Educação e Pesquisa, v. 30, n. 1, abr. 2004

KUENZER, A Z. O Ensino Médio agora é para a vida: entre o pretendido, o dito e o feito. Educação \& Sociedade, n. 70, abr. 2000.

MATOS, M. S. (et. al.) O impacto do programa de inclusão social da USP no acesso de estudantes de escola pública ao ensino superior público gratuito. Revista Brasileira de Estudos Pedagógicos, v. 93, n. 235, dez. 2012

MORIN, E. A cabeça bem feita: repensar a reforma, reformar o pensamento. Rio de Janeiro Bertrand Brasil, 2003.

PINHEIRO, N. M. (et. al.) Ciência, Tecnologia e Sociedade: a relevância do enfoque CTS para o contexto do Ensino Médio. Ciência \& Educação, v. 13, n. 1, 2007. 